be placed in an upright occlusal position, but it is not absolutely necessary that they be moved distally to their normal positions, for in adult patients this movement will very often result in an absorption of the process as a result of the extreme distance which they are removed. After the, second and third molars have been straightened up in a normal occlusal plane and occupy normal buccolingual relation, we do not believe that an ideal or normal mesio-distal position very greatly improves the masticating efficiency of those teeth.

In replacing missing molars, the manner of attachment will depend more or less upon other conditions present. However, if the second molar or second premolar is vital, we would prefer some form of attachment which allows them to remain vital. In other words, we would object to the "devitalization" of healthy teeth for the purpose of making an attachment to carry an artificial substitute. It is needless to say that all replaced molars should be attached at both ends in such a manner as to retain the bucco-lingual relation of the approximating teeth. The attachment should be made in such a manner as to allow physiologic movement of the attached teeth.

Again, we would caution all in considering the question of missing teeth. in orthodontic practice to remember that no one plan can be followed and that each case must be decided upon its merits which will take into consideration the age of the patient, the condition of the remaining teeth, the degree of development of the alveolar process, and lastly the occlusal efficiency of the plan that is decided upon. Fach case must be decided upon its own conditions and a plan that would be advantageous for one patient would not be the best plan for another.

\title{
Announcement of the Meeting of the National Dental Association
}

$\mathrm{T}^{\mathrm{H}}$ HE National Dental Association will hold its Twenty-second Annual Meeting in Chicago, August 5-9, 1918. The headquarters will be at the Auditorium and Congress Hotels situated on Michigan Avenue, corner of Congress street. All meetings, clinics and exhibits will be held in these two hotels, which are connected with an underground tunnel.

The important announcement at this time must be the warning "Reserve your rooms at once. Make reservations by mail direct to the hotel of your choice. Arrangements for parking cars should be made direct to the garage."

The following is a list of hotels and rates:

AUDITORIUM HOTEL, MICHIGAN BOULEVARD AND CONGRESS STREET

Single room without bath, $\$ 1.50$ and $\$ 2.00$ per day. day.

Single room with bath, $\$ 2.50$ to $\$ 4.00$ per
Double room without bath, $\$ 2.50$ and $\$ 3.00$ per day.

Double room with bath, $\$ 4.00, \$ 5.00$ and $\$ 6.00$ per day.

CONGRESS HOTEL AND ANNEX, MICHIGAN AVENUE AND CONGRESS STREET

Room, detached bath (one person), $\$ 2.00$, $\$ 2.50, \$ 3.00$ per day.

Room, private bath (one person), $\$ 3.00$, $\$ 3.50, \$ 4.00, \$ 5.00 \$ 6.00$ per day.

Room, detached bath (two persons), $\$ 3.00$, $\$ 4.00, \$ 5.00$ per day.
Room, private bath (two persons), $\$ 5.00$, $\$ 6.00, \$ 7.00$ per day.

Suites: Two connecting rooms, private bath (two persons), $\$ 6.00$ to $\$ 10.00$ per day.

Three or four persons, $\$ 8.00$ to $\$ 14.00$ per day.

Corner Suites: Parlor, bedroom, and private bath, $\$ 10.00$ to $\$ 50.00$ per day. 
THE FOLLOWING IS A LIST OF GARAGES AND RATES:

Our rates for storage are $\$ 1.00$ for the first 24 hours, and 75 cents each additional 24 hours. At these rates cars can be taken out for driving and reparked during the same 24 hour period at same charge.

Ciry Auto Parking Company, A. V. Jackson, Gen., Mgr.,

Michigan Ave, and Lake Street, Chicago, I11.

We are prepared to take care of thirty or forty cars during your convention, at a special rate of 75 cents per day, provided they notify us of their identity as a member of your Association.

Down Town Grarage,

A. I. Bemmer, Mgr.,

Michigan Blvd. and Eighth St. One thousand cars can be parked in Grant Park (on the Lake Front) free. The City of Chicago furnishes policemen to watch these cars.

-J. P. Buckley,

Chairman Publicity Committee.

GENERAL CLINIC

Arrangements are sufficiently advanced to promise the members of the Association that the General Clinic will be one of the great features of the 1918 meeting.

In conference with officers of the National Dental Association, the Committee in charge of the General Clinic carefully considered the nature of the clinic to be presented this year. After trying for the past few years new features in conducting the Clinic Program, it is the belief that a greater number will be served and benefited by holding a General Clinic, grouped into Sections:-namely-Operative, Prosthetic, Crown and Bridge Work, Orthodontia and Prophylaxis.

To make it-national in character, the president, of the different state societies, was requested to appoint two Clinicians and two associates from his state society.

$\mathrm{U}_{\mathrm{p}}$ to date, thirty-nine state societies are represented and the remaining nine will be represented before the publishing of the official program.

Far away Alaska is sending two and two associates, and to make the clinic more than national, in fact an allied affair, the Canadian Dental Association has promised ten of the best clinicians in the Dominion. In addition, there will be a few unit clinicians who will demonstrate principles that require more than two men.

It is safe to say that this clinic will be unique in the sense that every man on the program will either be present or be represented by his associate.

-Don M. Gallie, Chairman, General Clinic. 


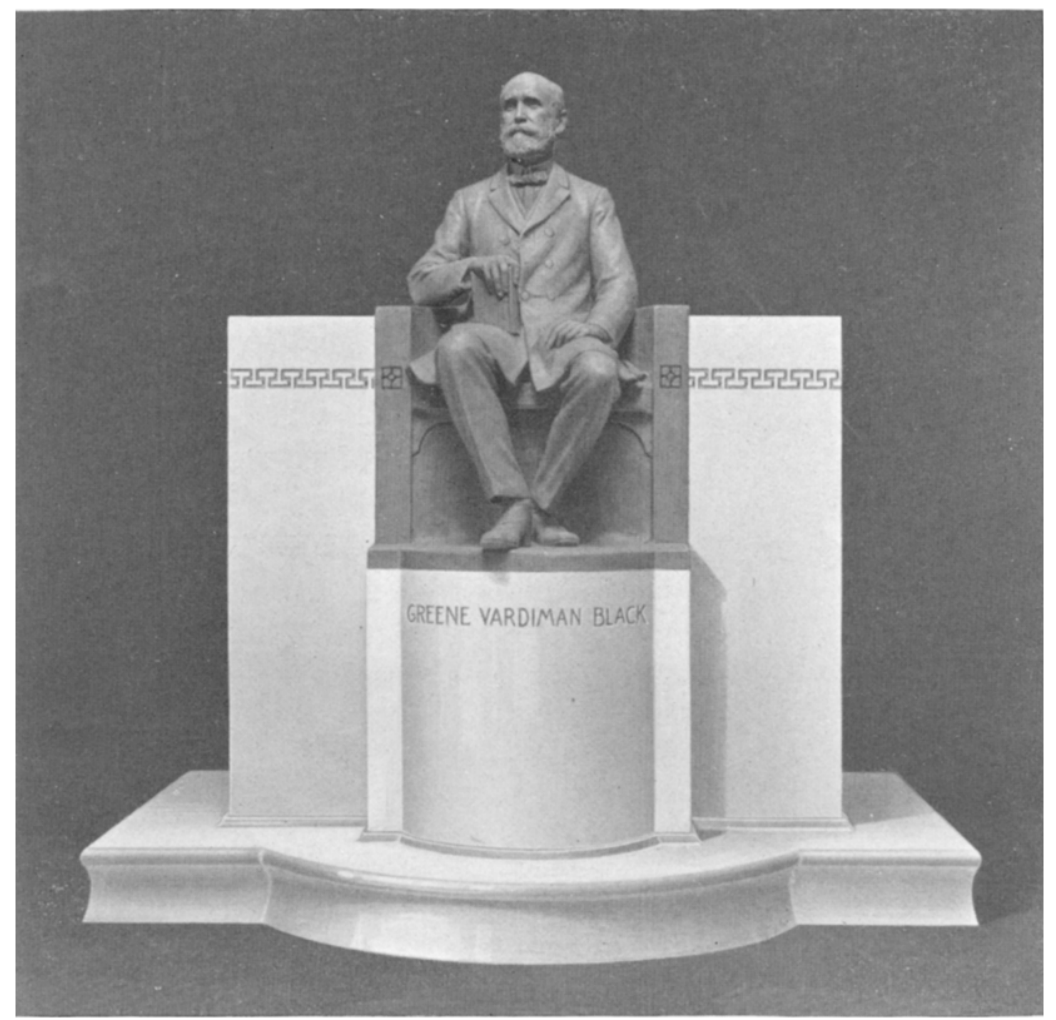

GREENE VARDIMAN BLACK MEMORIAL.

A Memorial from The National Dental Association. To be Dedicated at the 60th Anniversary Meeting to be held in Chicago, August 5-9, 1918. 